Biomedicine and Pharmacotherapy, 95, 2017, pp. 1725-1733.

\title{
The flavonoid 6-methoxyflavone allays cisplatin-induced neuropathic allodynia and hypoalgesia
}

\author{
Muhammad Shahid ${ }^{1,2}$, Fazal Subhan ${ }^{2}$, Nisar Ahmad ${ }^{2}$, Robert D.E. Sewell ${ }^{3}$
}

\begin{abstract}
Affiliations
${ }^{1}$ Department of Pharmacy, Sarhad University of Science and Information Technology, Peshawar, Pakistan

${ }^{2}$ Department of Pharmacy, University of Peshawar, Peshawar, Pakistan

${ }^{3}$ Cardiff School of Pharmacy and Pharmaceutical Sciences, Cardiff University, Cardiff. CF10 3NB.UK
\end{abstract}

\section{Email addresses}

Muhammad Shahid: shahidsalim_2002@hotmail.com

FazalSubhan: fazal_subhan@upesh.edu.pk

Nisar Ahmad: nisarahmadsatal@yahoo.com

Robert D.E. Sewell: sewell@ cardiff.ac.uk

\section{Correspondence}

Professor Fazal Subhan

Department of Pharmacy

University of Peshawar

Peshawar 25120

Khyber Pakhtunkhwa, Pakistan

Email: fazal_subhan@upesh.edu.pk

Muhammad Shahid

Email: shahidsalim_2002@hotmail.com 


\begin{abstract}
Chemotherapy-induced peripheral neuropathy (CIPN) is a major dose limiting side-effect of several commonly used chemotherapeutic agents (such as cisplatin) that profoundly impairs patient quality of life. Unfortunately, neither prophylactic strategies nor symptomatic treatments have proven useful in this condition. Flavonoids are found ubiquitously in fruits and vegetables and exert a multiplicity of beneficial effects. In this study, the antinociceptive activity of 6methoxyflavone (6-MF) was investigated and evaluated in comparison with gabapentin in a rat model of CIPN. The effect on motor balance was also assessed using the rotarod and footprint analysis paradigms. 6-MF possessed both peripheral and central antinociceptive activities against tonic and phasic nociceptive stimuli. Cisplatin administration (3.0 mg/kg/week, i.p.) for four consecutive weeks generated temporal mechanical allodynia (decreased paw withdrawal threshold; PWT) and thermal hypoalgesia (increased paw thermal threshold; PTT) in the bilateral hindpaws. Daily treatment with 6-MF (25, 50 and $75 \mathrm{mg} / \mathrm{kg} /$ day, i.p) for four weeks attenuated the cisplatininduced expression of nocifensive behaviors observed as a significant increase in PWT and alleviation of PTT during the third and fourth weeks of cisplatin administration. Accordingly, daily gabapentin (75 mg/kg, i.p) suppressed the expression of CIPN by normalizing the PWT and hotplate response latency. However, these antinociceptive actions were associated with motor impairment exemplified by a significant decrease in rotarod endurance latency and a deficit in the uniformity of step alternation. In contrast, 6-MF was devoid of these adverse side-effects. These findings suggested that 6-MF afforded desirable neuropathic pain alleviating effects in CIPN and it was devoid of gabapentin-like unwanted motor side-effects.
\end{abstract}

\title{
Key words
}

Flavone; antinociceptive; chemotherapy-induced neuropathic pain; natural product, pharmacotherapy; lack of motor incoordination. 


\section{Graphical Abstract}

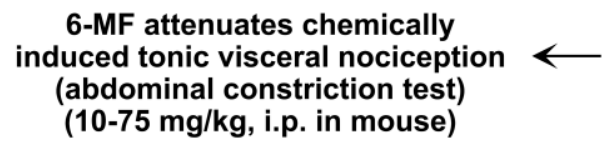

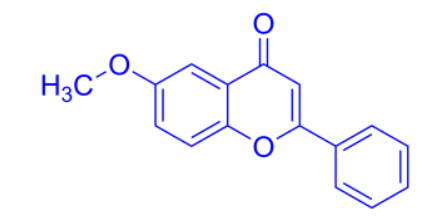

6-Methoxyflavone (6-MF) (25-75 $\mathrm{mg} / \mathrm{kg} /$ day i.p. for 28 days)

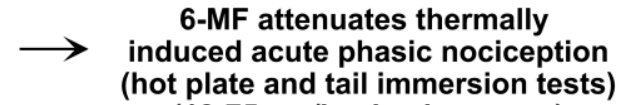

(10-75 $\mathrm{mg} / \mathrm{kg}$, i.p. in mouse)

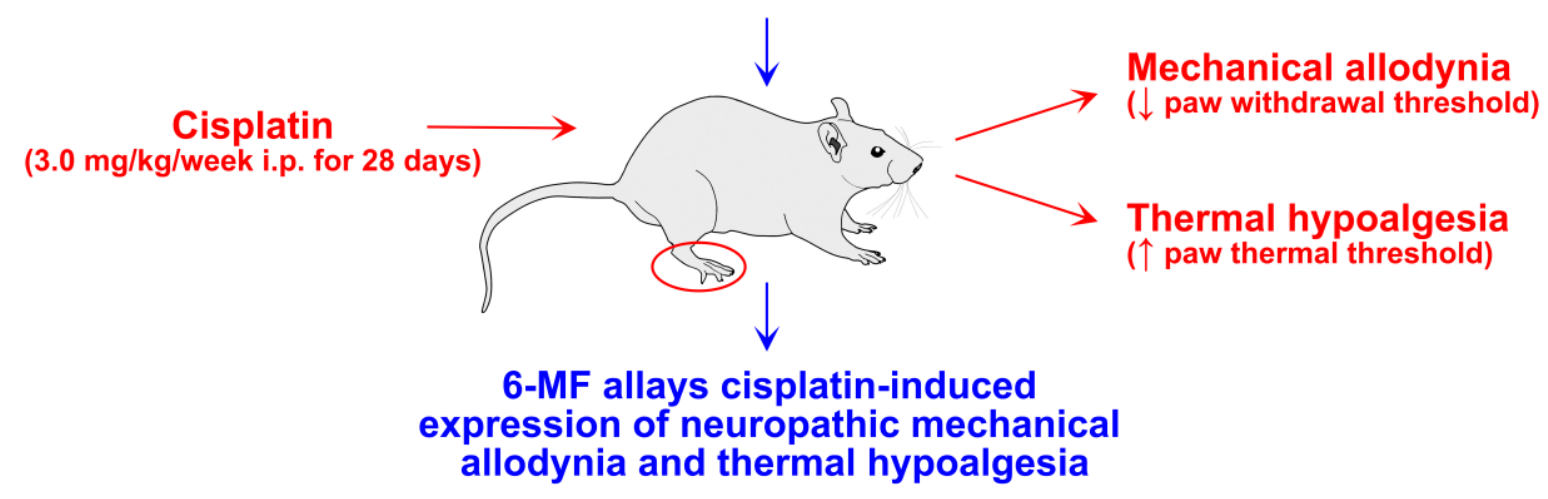

\section{Introduction}

Cisplatin, cisplatinum or cis-diamminedichloroplatinum, is a well-known chemotherapeutic drug used in the treatment of numerous human cancers including bladder, head and neck, lung, ovarian, and testicular cancers [1]. Its mode of action has been linked to an ability to crosslink with purine bases on DNA, interfering with DNA repair mechanisms, causing DNA damage, and subsequently inducing apoptosis in cancer cells [2]. Although cisplatin is a highly effective agent, it also has severe side effects, with neurotoxicity being one of the most common. The peripheral neuropathy resulting from cisplatin and other chemotherapeutic drugs is usually manifested by sensory disturbances which include both the negative symptom of numbness and the positive symptoms of pain and parasthesia. The sensory symptoms most frequently begin in the distal extremities in a 
'glove-and-stocking' distribution. These dose-limiting side-effects greatly hamper the course and effectiveness of chemotherapy with a severe degradation of patient quality of life [3-4].

Currently, the pharmacotherapy of chemotherapy-induced neuropathy (CIPN) remains largely ineffective. A variety of interventions including calcium and magnesium infusions, amifostine, antioxidants (glutathione, vitamin E, $\alpha$-lipoic acid and $N$-acetylcysteine) and anticonvulsant or antidepressant drugs (carbamazepine, lamotrigine, gabapentin, pregabalin or venlafaxine, duloxetine) have been tested in patients on chemotherapy. However, clinical outcomes have not been totally satisfactory $[3,5-6]$ and as a consequence, many patients are forced to dose-reduce or discontinue potentially curative chemotherapeutic drugs thus adversely affecting the oncologic end result. Hence, there is a large unmet medical need for novel, well-tolerated analgesic agents for improved relief of chemotherapy associated neuropathy.

Flavonoids are phenolic compounds composed of a three-ring structure with various substituents. They are found ubiquitously in fruit and vegetables and possess potent anti-inflammatory [7], antioxidant [8], anxiolytic [9-10] neuroprotective, [11] and antinociceptive properties [12]. They interact with many neurotransmitter systems such as serotonin, dopamine, $\gamma$-amino butyric acid (GABA) and glycine that are involved in neuroprotection and modulation of neuronal activity [13]. Flavonoids have displayed significant antinociceptive and neuroprotective effects in different models of neuropathies [14-16]. 6-Methoxyflavone (6-MF, Figure 1) belongs to the flavone class of flavonoids that acts as a flumazenil-insensitive positive allosteric modulator of GABA responses at human recombinant $\alpha 1 \beta 2 \gamma 2 \mathrm{~L}$ and $\alpha 2 \beta 2 \gamma 2 \mathrm{~L} \mathrm{GABA}_{\mathrm{A}}$ receptors expressed in Xenopus laevis oocytes [17]. 6-MF has also been shown to possess an immunomodulatory property and this action stems from its ability to suppress NFAT-mediated T-cell activation [18]. In the present investigation, the antinociceptive effectiveness of 6-MF was studied using the well-known testing 
paradigms of both tonic nociception (acetic acid induced abdominal constriction test) and phasic nociception (hotplate and tail immersion tests). Any propensity to attenuate CIPN was assessed in relation to gabapentin using a refined rat model of cisplatin-induced expression of neuropathic allodynia and thermal hypoalgesia. In addition, tests for motor coordination were carried out to evaluate the effect of 6-MF on neuronal function in comparison with gabapentin.

\section{Materials and methods}

\section{Drugs and reagents}

Cisplatin ( $\geq 99.9 \%$, Sigma-Aldrich, St. Louis, MO, USA), gabapentin (99.53\%, Lowitt Pharmaceuticals, Peshawar, Pakistan), 6-methoxyflavone (6-MF; 99\%, Sigma-Aldrich, St. Louis, MO, USA), acetic acid (PanReac AppliChem GmbH, Darmstadt, Germany), diclofenac sodium (Voren $^{\circledR}$ injection $75 \mathrm{mg} / 3.0 \mathrm{~mL}$, AsianContinental (Pvt) Ltd., Karachi, Pakistan), morphine (obtained through proper legal channels from Punjab Drug House, Lahore, Pakistan), dimethyl sulfoxide (DMSO, 99.5\%, Unichem, Greenville, USA), Tween 80 (80\%, Scharlau, Barcelona, Spain). 6-MF was dissolved in a vehicle comprised of DMSO, Tween-80 and normal saline in a ratio of 5:1:94.

\section{Animals}

BALB/c mice (18-24 g) and male Sprague-Dawley rats (200-250 g) bred in the Animal House of the Department of Pharmacy, University of Peshawar, Peshawar, Pakistan, were used in this study. The experimental procedures on animals were performed in compliance with the UK Animals (Scientific Procedures) Act 1986 and according to the rules and ethics of the Institutional Ethical Committee. Approval for the study was granted with the registration number: 13/EC-15/Pharm (dated: April 10, 2015). 


\section{Antinociceptive activity}

\section{Abdominal constriction test}

BALB/c mice of either sex (18-24 g, $n=8$ mice per group) were administered diclofenac sodium (50 mg/kg; i.p) and 6-MF (10, 25, 50 and $75 \mathrm{mg} / \mathrm{kg}$; i.p). After an interval of $30 \mathrm{~min}$, abdominal constriction behavior was induced by an intraperitoneal injection of $1 \%$ acetic acid solution [19]. The incidence of abdominal constrictions was counted over a period of $20 \mathrm{~min}$, commencing five min after acetic acid injection. The percentage antinociception was calculated using the following equation:

$\%$ Antinociception $=(1-$ number of abdominal constrictions in the treated group $/$ number of abdominal constrictions in the control group) $\times 100$

\section{Hotplate test}

$\mathrm{BALB} / \mathrm{c}$ mice of either sex (18-22 $\mathrm{g}, n=8$ mice per group) were pretested for their response latencies on a hotplate (Harvard apparatus, USA) maintained at $54.0 \pm 0.1^{\circ} \mathrm{C}$. The response endpoint was signified by hindlimb flick, lick or jumping, at which point animals were immediately removed from the thermal nociceptive stimulus to avoid any tissue damage or possibility of subsequent hyperalgesia. A cutoff time of $30 \mathrm{~s}$ was imposed such that if they did not respond within this latency period, then they were immediately removed from the hotplate stimulus [20]. Thirty min after pretesting, the animals were administered morphine $(5.0 \mathrm{mg} / \mathrm{kg}$; i.p, as positive control), or 6-MF $(10,25,50$ and $75 \mathrm{mg} / \mathrm{kg}$; i.p) and the response latencies were subsequently measured at 30,60 and $90 \mathrm{~min}$. The percentage antinociception was calculated using the equation:

$\%$ Antinociception $=($ test latency - control latency $) /($ cutoff time - control latency $) \times 100$ 


\section{Tail immersion test}

$\mathrm{BALB} / \mathrm{c}$ mice of either sex (18-22 $\mathrm{g}, n=8$ mice per group) were pretested for their response latencies by dipping the protruding $2 / 3$ end of tail in a water bath maintained at $50 \pm 0.8^{\circ} \mathrm{C}$. The response end-point was signified by tail withdrawal at which point animals were immediately removed from the thermal nociceptive stimulus to avoid any tissue damage or possibility of subsequent hyperalgesia. A cutoff time of $15 \mathrm{~s}$ was imposed such that if they did not respond within this latency period then they were immediately removed from the thermal stimulus [21]. Thirty minutes after pretesting, the animals were administered morphine $(5.0 \mathrm{mg} / \mathrm{kg}$; i.p, as a positive control), or 6-MF (10, 25, 50 and $75 \mathrm{mg} / \mathrm{kg}$; i.p) and the animal response latencies were measured at 30,60 and $90 \mathrm{~min}$. Percentage antinociception was calculated using the equation as mentioned above for the hotplate test.

\section{Induction of cisplatin-induced neuropathic nociception and the treatment protocol}

Cisplatin-induced neuropathic nociception was established in male Sprague-Dawley rats (200-250 g) using a validated paradigm consisting of four cisplatin injections $(3.0 \mathrm{mg} / \mathrm{kg})$ at weekly intervals as previously reported [22]. To avoid cisplatin-induced kidney damage, hyperhydration was induced by subcutaneous injection of $2.0 \mathrm{~mL}$ of sterile saline $5 \mathrm{~min}$ before administration of cisplatin. 6-MF was administered once daily in doses of 25,50 and $75 \mathrm{mg} / \mathrm{kg}$ via the intraperitoneal route [23]. Gabapentin was used as a positive control and was administered intraperitoneally once daily at a dose of $75 \mathrm{mg} / \mathrm{kg}$ (i.p) [24-25]. The animals were randomly divided into the following groups ( $n=6$ animals per group) and the study was continued for 28 days (4 weeks):

Group 1: Vehicle $(1.0 \mathrm{~mL} / \mathrm{kg} /$ day, i.p) 
Group 2: Cisplatin (3.0 mg/kg/week, i.p)

Group 3: Vehicle (1.0 mL/kg/day, i.p) + Cisplatin (3.0 mg/kg/week, i.p)

Group 4: 6-MF (25 mg/kg/day, i.p) + Cisplatin (3.0 mg/kg/week, i.p)

Group 5: 6-MF (50 mg/kg/day, i.p) + Cisplatin (3.0 mg/kg/week, i.p)

Group 6: 6-MF (75 mg/kg/day, i.p) + Cisplatin (3.0 mg/kg/week, i.p)

Group 7: Gabapentin (75 mg/kg/day, i.p) + Cisplatin (3.0 mg/kg/week, i.p)

Group 8: 6-MF (25 mg/kg/day, i.p)

Group 9: 6-MF (50 mg/kg/day, i.p)

Group 10: 6-MF (75 mg/kg/day, i.p)

Group 11: Gabapentin (75 mg/kg/day, i.p)

\section{Assessment of mechanical allodynia in the hindpaws}

Mechanical allodynia was assessed in rats using a series of 8 von Frey filaments $(0.4,0.70,1.20$, 2.00, 3.63, 5.50, 8.50, and $15.10 \mathrm{~g}$ ) (Stoelting, Wood Dale, Illinois, USA). The filaments were applied perpendicularly to the mid-plantar surface of the left hindpaw to an extent that caused the filaments to bend [26]. Each von Frey filament was applied for a period of up to $6 \mathrm{~s}$ as a cutoff time or until a positive response occurred. Lifting of the paw or flinching immediately upon removal of the filament was recorded as a positive response and a succeeding von Frey filament of lower force was applied for the following recording. In the case of an absence of response, the subsequent von Frey filament of higher force was applied. This procedure was continued until four measurements were taken after the first change in direction (positive response) or five consecutive negative responses $(2.00,3.63,5.50,8.50$ and $15.10 \mathrm{-g}$ force) or four consecutive positive responses $(2.00,1.20,0.70,0.4-\mathrm{g}$ force $)$. A force of $15.10 \mathrm{~g}$ was selected as the cutoff force at which point further application ceased. The filaments were applied at intervals of several seconds 
to avoid any influence of previous stimuli on behavior. Any ambulation was noted as an indefinite response, and the stimulus was repeated. The paw withdrawal threshold (PWT, g) was measured in both hindpaws with an interval of $5 \mathrm{~min}$ and the mean value was calculated from three readings. The pattern of each response was converted to the 50\% PWT.

\section{Assessment of thermal hypoalgesia in the hindpaws}

The thermal withdrawal latency was assessed in rats using a hotplate (Harvard apparatus, USA). The metallic testing plate was maintained at $52.0 \pm 0.2{ }^{\circ} \mathrm{C}$ and the response latency (paw thermal threshold, PTT) in seconds was recorded to the onset of escape jumping or lifting/licking of the hindpaws. In order to avoid tissue injury, the cutoff limit was set at $60 \mathrm{~s}$. Each response latency was measured in triplicate and the mean value from the three measurements was taken as the heat thermal nociceptive response latency [27].

\section{Assessment of motor coordination and balance}

\section{Rotarod}

A purpose built accelerating rotarod was used in which rats were placed on a rotating drum with the speed increasing from 4 to $40 \mathrm{rpm}$ over $5 \mathrm{~min}$, forcing them to walk forward to avoid falling off [24]. The latency to dismount from the rotarod was measured and each animal was given three trials on the test day before drug treatment. The effect on motor performance was then evaluated on days 7, 14, 21 and 28, $1 \mathrm{~h}$ post administration of 6-MF or gabapentin.

\section{Footprint analysis}

Gait analysis was performed in rats using footprint patterns (walking tracks) [24]. The forepaws and hindpaws of each animal were coated with two different colored nontoxic inks and they were 
allowed to walk along a narrow, white paper covered corridor, leaving a track of footprints. The footprints were allowed to dry and the patterns of the right side were measured for stride length (average distance of forward movement between each stride) and overlap between forepaw and hindpaw placement (distance between the front and hind footprints on each side). On the test day, each animal was given two trials before treatment. The effect was evaluated $1 \mathrm{~h}$ after administration of 6-MF or gabapentin on days 7, 14, 21 and 28.

\section{Statistical analysis}

The experimental data were expressed as mean \pm S.E.M. One-way analysis of variance (ANOVA) followed by post hoc Dunnett's test was used to analyze the abdominal constriction antinociceptive test data. Two-way repeated measures ANOVA followed by post hoc Bonferroni's test was used to compare the thermal response latencies in the phasic antinociceptive tests (hotplate and tail immersion) and pain behaviors in the cisplatin-induced neuropathic nociceptive model of CIPN between the drug treated groups and controls. When two groups were compared, two-sample $t$-test was used. The PWT and PTT data were converted to percentage anti-allodynia and anti-hyperalgesia, respectively according to the formula: anti-allodynia/anti-hypoalgesia $(\%)=$ [(drug-treated threshold or latency - cisplatin threshold or latency) / (cutoff threshold or latency cisplatin threshold or latency) $] \times 100$. The motor incoordination index was calculated as: motor incoordination $(\%)=(1-$ treated group dismount latency $/$ vehicle group dismount latency $) \times 100$. All statistical analyses were conducted using GraphPad Prism 5 (GraphPad Software Inc. San Diego CA, USA). A $P<0.05$ was considered as significant. 


\section{Results}

\section{Effect of 6-methoxyflavone on chemically induced tonic visceral nociception}

In the tonic chemically induced tonic nociceptive test in mice, administration of $1.0 \%$ acetic acid solution as anociceptive stimulus into the peritoneal cavity incited a marked nocifensive response observed as a significant increase in abdominal constrictions. This nocifensive response was significantly attenuated $(F(5,42)=25.36, P<0.0001)$ by the test doses of 6-MF and diclofenac. Treatment with 6-MF afforded a graded antinociceptive effect as it significantly abolished chemically induced tonic visceral nociception at $10-75 \mathrm{mg} / \mathrm{kg}(P<0.001)$ compared to vehicle treated controls. As shown in Table 1, an increased percentage antinociception was observed for $75 \mathrm{mg} / \mathrm{kg}(60.9 \%)$ followed by the $50 \mathrm{mg} / \mathrm{kg}(52.9 \%), 25 \mathrm{mg} / \mathrm{kg}(44.3 \%)$ and $10 \mathrm{mg} / \mathrm{kg}(30.6 \%)$ doses of 6-MF. Similarly, the positive control, diclofenac $(50 \mathrm{mg} / \mathrm{kg})$ also induced a robust antinociceptive effect $(53.8 \%, P<0.001)$.

\section{Effect of 6-methoxyflavone on thermally induced acute phasic nociception}

In the hotplate test in mice, treatment with either 6-MF or morphine produced significant changes in the thermal withdrawal latency $[$ time $=(F(2,105)=51.05, P<0.0001)$, treatment $=(F(5,105)$ $=92.58, P<0.0001)$, interaction $=(F(10,105)=9.19, P<0.0001)]$. The tested doses of 6-MF $(10,25,50,75$ and $100 \mathrm{mg} / \mathrm{kg})$ produced a dose-dependent antinociceptive effect against acute phasic thermal nociception as disclosed by a significant increase $(P<0.01$ and $P<0.001)$ in the percentage response latency observed during the 30-60 min (for all the tested doses) and $90 \mathrm{~min}$ (only for $25-75 \mathrm{mg} / \mathrm{kg}$ doses) of the study duration. During these time periods, the $75 \mathrm{mg} / \mathrm{kg}$ dose yielded maximum protection $(42.9 \%, 37.3 \%$ and $28.3 \%)$ followed by the $50 \mathrm{mg} / \mathrm{kg}(33.1 \%, 28.5 \%$ and $22.8 \%), 25 \mathrm{mg} / \mathrm{kg}(27.4 \%, 21.0 \%$ and $16.5 \%)$ and $10 \mathrm{mg} / \mathrm{kg}(19.1 \%, 14.6 \%$ and $11.1 \%)$ doses. 
The opioid agonist, morphine as a positive control, also afforded significant percentage protection (50.3\%, 27.2\% and 15.1\%; $P<0.001$ and $P<0.01)$ against thermal nociception during $30-90 \mathrm{~min}$ of the study-period compared to vehicle-treated control. The increase in the hotplate latencies produced by 6-MF (Table 2) which were comparable to that of morphine, signified its robust antinociceptive effect in this paradigm.

In the mouse tail immersion antinociceptive test, immersing the lower end of tail in warm water evoked a tail-withdrawal reflex which was temporally altered by treatment with either 6-MF or morphine $[$ time $=(F(2,105)=28.56, P<0.0001)$, treatment $=(F(5,105)=130.26, P<0.0001)$, interaction $=(F(10,105)=3.04, P=0.002)]$. Administration of 6-MF prolonged the tail withdrawal reaction time yielding a significant increase in the percent antinociception between 30$60 \mathrm{~min}$ (for all the tested doses, $P<0.001$ and $P<0.05$ ) and at $90 \mathrm{~min}$ (for $25-75 \mathrm{mg} / \mathrm{kg}, P<$ 0.001) after treatment. A graded percentage protection against acute phasic thermal nociception was provided by 6-MF with antinociception observed for the $75 \mathrm{mg} / \mathrm{kg}$ dose $(54.9 \%, 43.4 \%$ and $32.9 \%$ ) followed by the lower doses i.e. $50 \mathrm{mg} / \mathrm{kg}(41.4 \%, 30.97 \%$ and $23.0 \%)$ then $25 \mathrm{mg} / \mathrm{kg}$ $(33.5 \%, 25.5 \%$ and $17.4 \%)$ and $10 \mathrm{mg} / \mathrm{kg}(22.3 \%, 13.2 \%$ and $10.5 \%)$ at the 30,60 and $90 \mathrm{~min}$ post treatment times respectively. The positive control, morphine $(5.0 \mathrm{mg} / \mathrm{kg})$ exhibited a high-grade time-related protective effect and as such, it induced marked antinociception $(57.2 \%, 44.2 \%$ and $34.7 \%, P<0.001)$ (Table 2).

\section{Effect of 6-methoxyflavone on cisplatin-induced expression of neuropathic mechanical allodynia}

A single intraperitoneal administration of cisplatin $(3.0 \mathrm{mg} / \mathrm{kg} / \mathrm{week})$ in rats for 4 consecutive weeks generated mechanical allodynia in the bilateral hindpaws (Figure 2A). This was denoted by 
a progressive decrease in the PWT after week $1[5.9 \pm 0.9 \mathrm{~g} ; \mathrm{t}(5)=6.585, P=0.0012]$, week 2 $[3.7 \pm 0.9 \mathrm{~g} ; \mathrm{t}(5)=10.30, P=0.0001]$, week $3[3.4 \pm 1.3 \mathrm{~g} ; \mathrm{t}(5)=9.035, P=0.0003]$ and week 4 $[2.6 \pm 0.5 \mathrm{~g} ; \mathrm{t}(5)=12.52, P<0.0001]$ compared to respective vehicle-treated controls $(14.1 \pm 0.6$ $\mathrm{g}, 15.1 \pm 0.3 \mathrm{~g}, 14.1 \pm 0.6 \mathrm{~g}$ and $15.0 \pm 0.8 \mathrm{~g})$. Treatment with either 6-MF or gabapentin had beneficial effects on the cisplatin-induced nociception to innocuous von Frey filament pressure i.e. static mechanical allodynia $[$ time $=(F(4,225)=32.49, P<0.0001)$, treatment $=(F(9,225)=$ $84.52, P<0.0001)$, interaction $=(F(36,225)=5.01, P<0.0001)]$. Thus, when tested at doses of 25, 50 and $75 \mathrm{mg} / \mathrm{kg}, 6-\mathrm{MF}$ counteracted cisplatin-induced nociception exemplified by a significant increase $(P<0.05, P<0.001)$ in the PWT to gentle static-pressure stimuli when tested weekly for mechanical allodynia. The positive control, gabapentin $(75 \mathrm{mg} / \mathrm{kg})$, also had a similar attenuating effect manifested as a decrease in cisplatin-induced nociception $(P<0.001)$ throughout the experimental period i.e. from day 7 to 28 (Figure 2B). Evaluation of any anti-allodynia

propensity $[$ time $=(F(3,80)=0.75, P=0.5332)$, treatment $=(F(4,80)=31.57, P<0.0001)$, interaction $=(F(12,80)=0.49, P=0.9134)]$ also revealed a tactile anti-allodynic activity of 6-MF $(25,50$ and $75 \mathrm{mg} / \mathrm{kg})$ after day $7(22.4 \% ; 47.0 \%, P<0.05 ; 65.5 \%, P<0.001)$, day $14(33.3 \%$; $51.4 \%, P<0.01 ; 70.8 \%, P<0.001)$, day $21(40.1 \% ; 59.9 \%, P<0.001 ; 66.1 \%, P<0.001)$ and day $28(49.5 \%, P<0.01 ; 70.4 \%, P<0.001 ; 77.6 \%, P<0.001)$ respectively. Similarly, gabapentin $(75$ $\mathrm{mg} / \mathrm{kg}$ ) also produced a reversal of allodynia there being percentage anti-allodynia values of $72.1 \%$ after 28 days followed by $71.6 \%$ after 14 days, $69.3 \%$ after 7 days and $55.1 \%$ after 21 days, compared to the vehicle treated group (Figure 2C).

\section{Effect of 6-methoxyflavone on cisplatin-induced expression of neuropathic thermal hypoalgesia}

Single weekly injection of cisplatin over 4 consecutive weeks instigated temporal thermal hypoalgesia in rat bilateral hindpaws (Figure 3A). A neuropathic hypoalgesia which was expressed 
as an increase in the PTT was noted after the second cisplatin injection i.e. on day $14[23.3 \pm 1.8 \mathrm{~s}$; $\mathrm{t}(5)=2.647, P=0.0456]$ and remained significant for subsequent cisplatin dosing i.e. on day 21 $[31.8 \pm 1.6 \mathrm{~s} ; \mathrm{t}(5)=6.611, P=0.0012]$ and day $28[35.2 \pm 2.4 \mathrm{~s} ; \mathrm{t}(5)=7.272, P=0.0008]$ compared to that of vehicle alone treated controls over the corresponding period $(17.8 \pm 1.4 \mathrm{~s}, 18.8$ $\pm 0.8 \mathrm{~s}$ and $18.8 \pm 1.1 \mathrm{~s}$ respectively). Treatment with $6-\mathrm{MF}$ or gabapentin exerted significant protection against the cisplatin-induced temporal expression of heat-hypoalgesia [time $=(F(4$, $225)=21.37, P<0.0001)$, treatment $=(F(9,225)=8.74, P<0.0001)$, interaction $=(F(36,225)$ $=2.38, P<0.0001)]$. The neuropathic-hypoalgesic mitigating action of 6-MF was pronounced and all doses $(25-75 \mathrm{mg} / \mathrm{kg})$, decreased cisplatin elevated nociceptive response latencies on days 21 ( $P$ $<0.05, P<0.01)$ and $28(P<0.01, P<0.001)$ of the protocol. Likewise, the positive control, gabapentin $(75 \mathrm{mg} / \mathrm{kg})$ reduced cisplatin-induced neuropathic thermohypoalgesia on days $21(P<$ $0.01)$ and $28(P<0.001)$ (Figure 3B). An anti-neuropathic effect of 6-MF was also indicated by the percentage anti-hypoalgesic response $[$ time $=(F(3,80)=8.15, P=0.0010)$, treatment $=(F(4$, $80)=8.14, P<0.0001)$, interaction $=(F(12,80)=3.08, P=0.0013)]$. Consequently, 6-MF $(25$, 50 and $75 \mathrm{mg} / \mathrm{kg}$ ) attenuated the cisplatin generated thermal hypoalgesic response observed on protocol days $21(-21.7 \%, P<0.01 ;-25.6 \%, P<0.01 ;-25.2 \%, P<0.01)$ and $28(-27.0 \%, P<$ $0.01 ;-45.6 \%, P<0.001 ;-37.9 \%, P<0.001)$, respectively. The positive control, gabapentin $(75$ $\mathrm{mg} / \mathrm{kg}$ ) also showed a thermal anti-hypoalgesic effect by reversing the cisplatin augmented thermal withdrawal threshold $(-24.3 \%, P<0.01$ after 21 days and $-38.5 \%, P<0.001$ after 28 days in the protocol) (Figure 3C).

\section{Effect of 6-methoxyflavone on motor coordination and balance}

The effect of 6-MF or gabapentin on motor coordination was assessed in mice using the rotarod paradigm. A significant main effect of time $[F(4,225)=7.75, P=0.0003]$, treatment $[F(9,225)$ 
$=79.34, P<0.0001]$ and time $\times$ treatment interaction $[F(36,225)=6.34, P<0.0001]$ for rotorod dismount latency was observed. Treatment with gabapentin $(75 \mathrm{mg} / \mathrm{kg}$, i.p) was associated with motor incoordination as indicated by a profound decrease $(P<0.001)$ in the dismount latency observed in the gabapentin plus cisplatin and gabapentin alone treated-animals compared to vehicle-treated controls throughout. In comparison, there was no detectable deficit in motor control following treatment with 6-MF plus cisplatin or 6-MF alone over the dose range of 25-75 $\mathrm{mg} / \mathrm{kg}$. The cisplatin controls did not display any motor incoordination as there was no change in the rotarod latency over the entire study duration (Figure 4A). The motor incoordination index [time $=(F(3,100)=1.03, P=0.4007)$, treatment $=(F(5,100)=89.74, P<0.0001)$, interaction $=$ $(F(15,100)=0.23, P=0.9988)]$ also confirmed the absence of motoric side-effects with 6-MF in contrast to gabapentin which produced a marked motor deficit from day 1-28. Interestingly, the motor incoordination index also revealed a lack of muscular coordination for cisplatin after 28 days when motor discoordination was statistically detected (Figure 4B).

Gait analysis of footprint patterns (walking tracks) further corroborated the impact of 6-MF and gabapentin on motor coordination. A significant change was observed in the overlap between the forepaw and hindpaw placement $[$ time $=(F(4,225)=5.42, P=0.0028)$, treatment $=(F(9,225)=$ 33.73, $P<0.0001)$, interaction $=(F(36,225)=2.43, P<0.0001)]$. The animals administered daily with gabapentin $(75 \mathrm{mg} / \mathrm{kg}$, i.p) plus weekly cisplatin produced significant foot displacement $(P<0.001)$ during the entire study duration compared to the vehicle-treated controls (Figure 5A). Likewise, gabapentin treatment alone resulted in a deficit $(P<0.001)$ in the uniformity of step alternation. Conversely, the cisplatin control or the 6-MF $(25-75 \mathrm{mg} / \mathrm{kg})$ plus cisplatin treated groups, as well as those treated alone with 6-MF, displayed no effect $(P>0.05)$ on the distance between the center of ipsilateral footprints throughout the study period. Moreover, neither the 
cisplatin control, nor the treatments had any effect on stride length $[$ time $=[F(4,225)=0.98, P=$ $0.4358]$, treatment $=[F(9,225)=4.77, P<0.0001]$, interaction $[F(36,225)=0.93, P=0.5948]$ (Figure 5B).

\section{Discussion}

The present study investigated the antinociceptive properties of 6-MF and explored its prospective effectiveness to alleviate chemotherapy-induced peripheral neuropathy (CIPN) in a refined rat model of this pathological condition. The antinociceptive effect was evaluated using the acetic acid-induced abdominal constriction assay, as well as the hotplate and tail immersion tests. These paradigms are suitable for assessing both tonic visceral nociception and centrally mediated acute phasic nociception, respectively [21, 28-30]. Acetic acid provokes a visceral reaction termed an abdominal constriction response [28] which is indicative of peritoneovisceral pain. This arises most probably from the liberation of endogenous substances, especially the prostaglandins, via the action of the constitutive enzyme cyclooxygenase-1 (COX-1) and its isoform COX-2 [31]. These nociceptive reflexes are sensitive to analgesics that suppress the generation of tonic nociception by interacting with $\alpha_{1 / 2}$-adrenoceptors, $\beta$-adrenoceptors and opioid receptors on the terminals of sensory afferents in the peritoneum [32-33]. The results from the abdominal constriction assay suggested that 6-MF potentially possesses a peripheral analgesic action, in all probability mediated through inhibition or activation of local peritoneal receptors or inhibition of cyclooxygenase enzymes. The typical non-steroidal anti-inflammatory drug, diclofenac has been shown to exhibit a similar antinociceptive profile in this tonic pain model [34]. A central analgesic property of 6-MF was evaluated by the hotplate and tail immersion methods. Prolongation of thermal response latencies in both tests implied that mediation of the antinociceptive effect of 6-MF might be attributed to a decrease in pain transmission by activation of descending nerve fibers supraspinally, 
and inhibition of afferent nerve transmission by binding to spinal opioid receptors [35]. A similar response has been observed with the opioid agonist, morphine. Previously, it has been reported that 7-methoxyflavone (7MF) isolated from Zornia brasiliensis reduces abdominal constriction behavior, inhibits the neurogenic phase of the formalin pain response and decreases glutamateinduced nociception without affecting the thermal response latency in the hotplate test [36]. The inability of 7MF to modify hotplate latency may be ascribed to the use of lower doses $(\leq 300$ $\mu \mathrm{mol} / \mathrm{kg}$, i.p.) compared to 6-MF ( $\leq 75 \mathrm{mg} / \mathrm{kg}$, i.p.) which increased thermal response latencies in both hotplate and tail immersion phasic pain paradigms in this study. Moreover, the differences in central analgesic activity may also be due to the position of the methoxy group on the flavone nucleus, since substitutions in the basic ring structure profoundly affect the biological activity of flavonoids [37-38]. Furthermore, introduction of methoxy groups confers unfavorable steric effects and increases both lipophilicity and membrane partitioning [37]. Consequently, structure activity relationships should be taken into account in developing flavonoids with high therapeutic index [39].

CIPN is a severe side-effect of cytostatic pharmacotherapy, particularly platinum compounds like cisplatin, which are associated with a length dependent neuropathy that primarily affects the distal sites, and as doses increase cumulatively, symptoms progress in severity to more proximal areas [40]. The severity of CIPN is dependent on the chemotherapeutic agent, duration of therapy, cumulative dose, and concomitant use of other neurotoxic agents [41]. Different chemotherapies affect distinct components of the nervous system, from the level of sensory cell bodies in the dorsal root ganglion (DRG) to the distal axon. The DRG is a prominent target as it is less protected by the blood-nerve barrier and more vulnerable to neurotoxic damage potentially explaining the predominance of sensory involvement in patients with CIPN. Platinum compounds accumulate in 
the DRG with platinum-DNA adducts leading to cell death in sensory neurons [4]. Animal models have been used to evaluate anticancer drug-induced neuropathies in a search for potential therapies to prevent or at least minimize nerve damage [42-43]. In this respect, the cisplatin-induced rat model of CIPN is currently regarded as being suitable for analgesic efficacy profiling of novel compounds and for comparative investigation of the pathobiology of this condition relative to that of CIPN induced by other cancer chemotherapy agents [22]. In this study, weekly injection of cisplatin $(3.0 \mathrm{mg} / \mathrm{kg}$ for four consecutive weeks) produced temporal development of neuropathic mechanical allodynia and hypoalgesia in the bilateral hindpaws and this expression of neuropathy was consistent with previous reports concerning the cisplatin-induced neuropathic pain model [22, 42]. In the current study, mechanical allodynia and thermal hypoalgesia were selected as the parameters to assess the development of peripheral neuropathic pain because low animal stress levels are involved [44] and the heat-hypoalgesia reflects clinical reports of patients with CIPN. Treatment with cisplatin incurs a loss of large myelinated fibers, especially in the distal part of the nerve and abnormalities in the myelin sheath of medium fibers [45]. What is more, the development of mechanical allodynia and loss of noxious heat sensitivity reported in this study may well result from damage to myelinated $\alpha \beta$ fibers with concurrent depletion of C-fibers [46].

There are no established agents recommended for the prevention of CIPN in patients with cancer undergoing treatment with neurotoxic agents. Duloxetine along with gabapentin and a compounded topical gel containing baclofen, amitriptyline, and ketamine do offer some therapeutic utility in the management of CIPN [47]. In this study, gabapentin was employed as a positive control and it produced a beneficial effect by attenuating the overall expression of cisplatin-induced aberrations in nociceptive behaviors. Gabapentin is probably the most worthwhile agent used in the treatment of neuropathic pain conditions and its efficacy has been 
established in several preclinical models and clinical trials on neuropathic pain [48-50]. It is effective in the treatment of cancer-related neuropathic pain in patients undergoing chemotherapy [51] and produces a dose dependent relief of mechanical allodynia in the bilateral hindpaws of cisplatin-induced peripheral neuropathic rats [22]. Unfortunately, the effectiveness of gabapentin in patients suffering from neuropathic pain is limited by the occurrence of side-effects such as dizziness, somnolence, ataxia, lethargy and convulsions [52]. This has been confirmed in different testing paradigms where gabapentin produced considerable impairment of motor coordination and balance.

Complementary and alternative medicines, especially herbal medicines, are well known for their multifaceted implications and are widely employed in human healthcare [53-54]. To date, several phytochemicals, plant extractions, and herbal formulas have been evaluated for their potential therapeutic benefit in preventing the onset and progression of CIPN in experimental models [55]. Isolated bioactive moieties from the flavonoid class are recognized as promising in different neuropathic pain conditions $[14,16,23]$. In the present study, the flavonoid, 6-MF allayed cisplatin-induced expression of neuropathic allodynia and thermal hypoalgesia whilst being devoid of the motor impairment associated with gabapentin. Other flavonoids like rutin and quercitin inhibit oxaliplatin-induced chronic peripheral neuropathy by preventing oxidative stress-induced damage in dorsal horn neurons [14]. Given the molecular complexity of the neuropathic pain mediating effect of platinum compounds (enhanced activity of ligand-gated and voltage-gated ion channels including TRP channels, oxidative stress and inflammation) [46], it could be speculated that multiple mechanisms may be similarly involved in the attenuation of CIPN by 6-MF. Correspondingly, flavonoids may activate or block members of the TRP channel superfamily, in particular TRPV4 and TRPM3 [56]. Moreover, flavonoids are well-documented for their potent 
antioxidant activity. The ability of flavonoids, in common with many polyphenols, to perform as antioxidants is widely considered to be an important aspect of their ability to act as neuroprotectives [13]. Additionally, flavonoids have a wide range of targets that lead to suppression of inflammation which has been closely linked to cancer [57]. They possess analgesic activity without addictive propensity, few adverse reactions and derive from rich resources in nature. They are becoming promising candidates as novel natural analgesic drugs [58] and the lack of effective therapeutic strategies for CIPN has boosted the need for the use of medicinal herbs and phytochemicals. These have gained increasing attention as a major form of alternative therapy because they are convenient, economical, effective and safe. Owing to the diverse mechanisms of CIPN, the outcomes of phytotherapy or herbs aimed at the multiple targets of CIPN appear to be encouraging [59].

\section{Conclusion}

6-MF possessed antinociceptive activity against both tonic and phasic nociceptive stimuli. Daily administration of 6-MF also reduced the cisplatin-induced temporal expression of mechanical allodynia and heat hypoalgesia in rat bilateral hindpaws following once weekly treatment in a four-week CIPN paradigm. On the other hand, at antinociceptive doses, 6-MF was devoid of the motor deficits observed with gabapentin, so it offers the advantage that it lacks side-effects routinely associated with gabapentin treatment. Therefore, 6-MF is a novel antinociceptive agent which might be a therapeutic option in the management of neuropathic pain associated with chemotherapy bearing in mind the limited effectiveness of currently available CIPN treatments. However, similar investigations in other animal models, along with mechanistic studies are warranted to obtain a deeper insight on the value of 6-MF on CIPN in a clinical setting. 


\section{Acknowledgements}

The authors are grateful to Lowitt Pharmaceuticals (Pvt.) Ltd., Peshawar, Pakistan for the donation of gabapentin active material for this study.

\section{Conflict of interest}

The authors declare no conflicts of interest.

\section{References}

[1] L. Kelland, The resurgence of platinum-based cancer chemotherapy, Nat. Rev. Cancer 7(8) (2007) 573-584.

[2] S. Dasari, P.B. Tchounwou, Cisplatin in cancer therapy: molecular mechanisms of action, Eur. J. Pharmacol. 740 (2014) 364-378.

[3] T.J. Kaley, L.M. DeAngelis, Therapy of chemotherapy-induced peripheral neuropathy, Br. J. Haematol. 145(1) (2009) 3-14.

[4] S.B. Park, D. Goldstein, A.V. Krishnan, C.S.Y. Lin, M.L. Friedlander, J. Cassidy, M. Koltzenburg, M.C. Kiernan, Chemotherapy-induced peripheral neurotoxicity: A critical analysis, CA. Cancer J. Clin. 63(6) (2013) 419-437.

[5] G. Cavaletti, P. Marmiroli, Chemotherapy-induced peripheral neurotoxicity, Nat. Rev. Neurol. 6(12) (2010) 657-666.

[6] J.W. Albers, V. Chaudhry, G. Cavaletti, R.C. Donehower, Interventions for preventing neuropathy caused by cisplatin and related compounds, The Cochrane Library (3) (2014) Art. No.: CD005228.1-97.

[7] W. Dong, T. Wei, Y. Guang-Ming, C. Bao-Chang, Anti-inflammatory, antioxidant and cytotoxic activities of flavonoids from Oxytropis falcata Bunge, Chin. J. Nat. Med. 8(6) (2010) 461-465. 
[8] K.E. Heim, A.R. Tagliaferro, D.J. Bobilya, Flavonoid antioxidants: chemistry, metabolism and structure-activity relationships, J. Nutr. Biochem. 13(10) (2002) 572-584.

[9] E. Ognibene, P. Bovicelli, W. Adriani, L. Saso, G. Laviola, Behavioral effects of 6bromoflavanone and 5-methoxy-6, 8-dibromoflavanone as anxiolytic compounds, Prog. Neuropsychopharmacol. Biol. Psychiatry 32(1) (2008) 128-134.

[10] S. Akbar, F. Subhan, N. Karim, U. Aman, S. Ullah, M. Shahid, N. Ahmad, K. Fawad, R.D. Sewell, Characterization of 6-methoxyflavanone as a novel anxiolytic agent: A behavioral and pharmacokinetic approach, Eur. J. Pharmacol. 801 (2017) 19-27.

[11] N. Cho, K.Y. Lee, J. Huh, J.H. Choi, H. Yang, E.J. Jeong, H.P. Kim, S.H. Sung, Cognitiveenhancing effects of Rhus verniciflua bark extract and its active flavonoids with neuroprotective and anti-inflammatory activities, Food Chem. Toxicol. 58 (2013) 355-361.

[12] Y. Wang, P. Chen, C. Tang, Y. Wang, Y. Li, H. Zhang, Antinociceptive and antiinflammatory activities of extract and two isolated flavonoids of Carthamus tinctorius L, J. Ethnopharmacol. 151(2) (2014) 944-950.

[13] G.A. Johnston, Flavonoid nutraceuticals and ionotropic receptors for the inhibitory neurotransmitter GABA, Neurochem. Int. 89 (2015) 120-125.

[14] M.I. Azevedo, A.F. Pereira, R.B. Nogueira, F.E. Rolim, G.A. Brito, D.V.T. Wong, R.C. Lima-Júnior, R. de Albuquerque Ribeiro, M.L. Vale, The antioxidant effects of the flavonoids rutin and quercetin inhibit oxaliplatin-induced chronic painful peripheral neuropathy, Mol. Pain 9(1) (2013) 53.

[15] A.D. Kandhare, K.S. Raygude, V.S. Kumar, A.R. Rajmane, A. Visnagri, A.E. Ghule, P. Ghosh, S.L. Badole, S.L. Bodhankar, Ameliorative effects quercetin against impaired motor nerve function, inflammatory mediators and apoptosis in neonatal streptozotocin-induced diabetic neuropathy in rats, Biomed. Aging Pathol. 2(4) (2012) 173-186.

[16] S. Çivi, G. Emmez, Ü.A. Dere, A.Ö. Börcek, H. Emmez, Effects of quercetin on chronic constriction nerve injury in an experimental rat model, Acta Neurochir. (Wien) 158(5) (2016) 959-965.

[17] B.J. Hall, N. Karim, M. Chebib, G.A. Johnston, J.R. Hanrahan, Modulation of Ionotropic GABA Receptors by 6-Methoxyflavanone and 6-Methoxyflavone, Neurochem. Res. 39(6) (2014) 1068-1078.

[18] J.-S. So, G.-C. Kim, M. Song, C.-G. Lee, E. Park, H.J. Kim, Y.S. Kim, C.-D. Jun, S.-H. Im, 6-Methoxyflavone inhibits NFAT translocation into the nucleus and suppresses $\mathrm{T}$ cell activation, J. Immunol. 193(6) (2014) 2772-2783. 
[19] H. Collier, L. Dinneen, C.A. Johnson, C. Schneider, The abdominal constriction response and its suppression by analgesic drugs in the mouse, Br. J. Pharmacol. Chemother. 32(2) (1968) 295-310.

[20] G. Woolfe, A. MacDonald, The evaluation of the analgesic action of pethidine hydrochloride (Demerol), J. Pharmacol. Exp. Ther. 80(3) (1944) 300-307.

[21] K. Ramabadran, M. Bansinath, H. Turndorf, M.M. Puig, Tail immersion test for the evaluation of a nociceptive reaction in mice: Methodological considerations, J. Pharmacol. Methods 21(1) (1989) 21-31.

[22] F.Y. Han, B.D. Wyse, M.T. Smith, Optimization and pharmacological characterization of a refined cisplatin-induced rat model of peripheral neuropathic pain, Behav. Pharmacol. 25(8) (2014) 732-740.

[23] S. Akbar, F. Subhan, N. Karim, M. Shahid, N. Ahmad, G. Ali, W. Mahmood, K. Fawad, 6Methoxyflavanone attenuates mechanical allodynia and vulvodynia in the streptozotocininduced diabetic neuropathic pain, Biomed. Pharmacother. 84 (2016) 962-971.

[24] M. Shahid, F. Subhan, N. Ahmad, G. Ali, S. Akbar, K. Fawad, R. Sewell, Topical gabapentin gel alleviates allodynia and hyperalgesia in the chronic sciatic nerve constriction injury neuropathic pain model, Eur. J. Pain 21(4) (2017) 668-680.

[25] M. Shahid, F. Subhan, N. Ahmad, I. Ullah, A bacosides containing Bacopa monnieri extract alleviates allodynia and hyperalgesia in the chronic constriction injury model of neuropathic pain in rats, BMC Complement. Altern. Med. 17(1) (2017) 293.

[26] S. Chaplan, F. Bach, J. Pogrel, J. Chung, T. Yaksh, Quantitative assessment of tactile allodynia in the rat paw, J. Neurosci. Methods 53(1) (1994) 55-63.

[27] C. Huang, Z.-P. Hu, H. Long, Y.-S. Shi, J.-S. Han, Y. Wan, Attenuation of mechanical but not thermal hyperalgesia by electroacupuncture with the involvement of opioids in rat model of chronic inflammatory pain, Brain Res. Bull. 63(2) (2004) 99-103.

[28] D. Le Bars, M. Gozariu, S.W. Cadden, Animal models of nociception, Pharmacol. Rev. 53(4) (2001) 597-652.

[29] U. Aman, F. Subhan, M. Shahid, S. Akbar, N. Ahmad, G. Ali, K. Fawad, R.D. Sewell, Passiflora incarnata attenuation of neuropathic allodynia and vulvodynia apropos GABAergic and opioidergic antinociceptive and behavioural mechanisms, BMC Complement. Altern. Med. 16(1) (2016) 1.

[30] N. Ahmad, F. Subhan, N.U. Islam, M. Shahid, F.U. Rahman, K. Fawad, A Novel Pregabalin Functionalized Salicylaldehyde Derivative Afforded Prospective Pain, Inflammation, and Pyrexia Alleviating Propensities, Arch. Pharm. (Weinheim) 350(6) (2017) doi: 10.1002/ardp.201600365. 
[31] H. Matsumoto, H. Naraba, A. Ueno, T. Fujiyoshi, M. Murakami, I. Kudo, S. Oh-ishi, Induction of cyclooxygenase- 2 causes an enhancement of writhing response in mice, Eur. J. Pharmacol. 352(1) (1998) 47-52.

[32] Y. Ikeda, A. Ueno, H. Naraba, S. Oh-ishi, Involvement of vanilloid receptor VR1 and prostanoids in the acid-induced writhing responses of mice, Life Sci. 69(24) (2001) 29112919.

[33] P. Honore, J. Mikusa, B. Bianchi, H. McDonald, J. Cartmell, C. Faltynek, M.F. Jarvis, TNPATP, a potent $\mathrm{P}_{2} \mathrm{X}_{3}$ receptor antagonist, blocks acetic acid-induced abdominal constriction in mice: comparison with reference analgesics, Pain 96(1) (2002) 99-105.

[34] F. Subhan, M. Abbas, K. Rauf, M. Arfan, R.D. Sewell, G. Ali, The role of opioidergic mechanism in the activity of Bacopa monnieri extract against tonic and acute phasic pain modalities, Pharmacologyonline 3 (2010) 903-914.

[35] T. Yaksh, Pharmacology and mechanisms of opioid analgesic activity, Acta Anaesthesiol. Scand. 41(1) (1997) 94-111.

[36] A.D.S. da Silva, L.H.A. Cavalcante-Silva, C.B.B. da Matta, D.d.F. Silva, M.V.d. Araújo, J.F. Tavares, M.S. da Silva, M.S. Alexandre-Moreira, Antinociceptive effect of 7methoxyflavone isolated from Zornia brasiliensis, Nat. Prod. Res. 27(18) (2013) 1695-1699.

[37] K.E. Heim, A.R. Tagliaferro, D.J. Bobilya, Flavonoid antioxidants: chemistry, metabolism and structure-activity relationships, J. Nutr. Biochem. 13(10) (2002) 572-584.

[38] V. Jacob, T. Hagai, K. Soliman, Structure-activity relationships of flavonoids, Curr. Org. Chem. 15(15) (2011) 2641-2657.

[39] J.-M. Jeong, C.-H. Choi, S.-K. Kang, I.-H. Lee, J.-Y. Lee, H. Jung, Antioxidant and chemosensitizing effects of flavonoids with hydroxy and/or methoxy groups and structureactivity relationship, J. Pharm. Pharm. Sci. 10(4) (2007) 537-546.

[40] W. Grisold, G. Cavaletti, A.J. Windebank, Peripheral neuropathies from chemotherapeutics and targeted agents: diagnosis, treatment, and prevention, Neuro-oncol. 14(suppl 4) (2012) iv45-iv54.

[41] D. Pachman, D. Barton, J. Watson, C.L. Loprinzi, Chemotherapy - Induced Peripheral Neuropathy: Prevention and Treatment, Clin. Pharmacol. Ther. 90(3) (2011) 377-387.

[42] N. Authier, J.-P. Gillet, J. Fialip, A. Eschalier, F. Coudore, An animal model of nociceptive peripheral neuropathy following repeated cisplatin injections, Exp. Neurol. 182(1) (2003) 1220.

[43] N. Nozaki-Taguchi, S.R. Chaplan, E.S. Higuera, R.C. Ajakwe, T.L. Yaksh, Vincristineinduced allodynia in the rat, Pain 93(1) (2001) 69-76. 
[44] G. Vera, A. Chiarlone, P.A. Cabezos, D. Pascual, M.I. Martín, R. Abalo, WIN 55,212-2 prevents mechanical allodynia but not alterations in feeding behaviour induced by chronic cisplatin in the rat, Life Sci. 81(6) (2007) 468-479.

[45] F.R. Luo, S.D. Wyrick, S.G. Chaney, Comparative neurotoxicity of oxaliplatin, ormaplatin, and their biotransformation products utilizing a rat dorsal root ganglia in vitro explant culture model, Cancer Chemother. Pharmacol. 44(1) (1999) 29-38.

[46] M. Sisignano, R. Baron, K. Scholich, G. Geisslinger, Mechanism-based treatment for chemotherapy-induced peripheral neuropathic pain, Nat. Rev. Neurol. 10(12) (2014) 694707.

[47] D.L. Hershman, C. Lacchetti, R.H. Dworkin, E.M. Lavoie Smith, J. Bleeker, G. Cavaletti, C. Chauhan, P. Gavin, A. Lavino, M.B. Lustberg, Prevention and management of chemotherapy-induced peripheral neuropathy in survivors of adult cancers: American Society of Clinical Oncology clinical practice guideline, J. Clin. Oncol. 32(18) (2014) 19411967.

[48] M. Rowbotham, N. Harden, B. Stacey, P. Bernstein, L. Magnus-Miller, G.P.N.S. Group, Gabapentin for the treatment of postherpetic neuralgia: a randomized controlled trial, JAMA 280(21) (1998) 1837-1842.

[49] M. Field, R. Oles, A. Lewis, S. McCleary, J. Hughes, L. Singh, Gabapentin (neurontin) and S-(+)-3-isobutylgaba represent a novel class of selective antihyperalgesic agents, Br. J. Pharmacol. 121(8) (1997) 1513-1522.

[50] G. Ali, F. Subhan, M. Abbas, J. Zeb, M. Shahid, R.D. Sewell, A streptozotocin-induced diabetic neuropathic pain model for static or dynamic mechanical allodynia and vulvodynia: Validation using topical and systemic gabapentin, Naunyn. Schmiedebergs Arch. Pharmacol. 388 (2015) 1129-1140.

[51] J. Ross, K. Goller, J. Hardy, J. Riley, K. Broadley, R. A'hern, J. Williams, Gabapentin is effective in the treatment of cancer-related neuropathic pain: A prospective, open-label study, J. Palliat. Med. 8(6) (2005) 1118-1126.

[52] M. Rose, P. Kam, Gabapentin: Pharmacology and its use in pain management, Anaesthesia 57(5) (2002) 451-462.

[53] M. Shahid, F. Subhan, I. Ullah, G. Ali, J. Alam, R. Shah, Beneficial effects of Bacopa monnieri extract on opioid induced toxicity, Heliyon 2(2) (2016) e00068.

[54] T. Sen, S.K. Samanta, Medicinal plants, human health and biodiversity: a broad review, Biotechnological Applications of Biodiversity, Springer2014, pp. 59-110. 
[55] X.L. Cheng, H.Q. Liu, Q. Wang, J.G. Huo, X.N. Wang, P. Cao, Chemotherapy-induced peripheral neurotoxicity and complementary and alternative medicines: progress and perspective, Front. Pharmacol. 6 (2015) 234.

[56] P. Holzer, A.A. Izzo, The pharmacology of TRP channels, Br. J. Pharmacol. 171(10) (2014) 2469-2473.

[57] S. Prasad, K. Phromnoi, V.R. Yadav, M.M. Chaturvedi, B.B. Aggarwal, Targeting inflammatory pathways by flavonoids for prevention and treatment of cancer, Planta Med. 76(11) (2010) 1044-1063.

[58] C. Brami, T. Bao, G. Deng, Natural products and complementary therapies for chemotherapy-induced peripheral neuropathy: A systematic review, Crit. Rev. Oncol. Hematol. 98 (2016) 325-334.

[59] G. Lee, S.K. Kim, Therapeutic effects of phytochemicals and medicinal herbs on chemotherapy-induced peripheral neuropathy, Molecules 21(9) (2016) 1252.

\section{FIGURE LEGENDS}

Figure 1: Chemical structure of 6-methoxyflavone.

Figure 2: Effect of daily treatment of rats with 6-methoxyflavone (6-MF) at $25 \mathrm{mg} / \mathrm{kg}$ (6-MF-25), $50 \mathrm{mg} / \mathrm{kg}$ (6-MF-50), and $75 \mathrm{mg} / \mathrm{kg}$ (6-MF-75) and gabapentin (GBP) at $75 \mathrm{mg} / \mathrm{kg}$ (GBP-75) on the expression of cisplatin-induced mechanical allodynia [diminished von Frey filament threshold pressure (paw withdrawal threshold; PWT in g)] in the hindpaws after weekly i.p. injection of cisplatin at $3.0 \mathrm{mg} / \mathrm{kg}$ (Cis-3) for four consecutive weeks in rats. (A) Temporal development of cisplatin-induced mechanical allodynia in the hindpaws. (B) Effect of 6-MF and gabapentin on cisplatin-induced expression of mechanical allodynia. (C) The percentage anti-allodynia of 6-MF and gabapentin. Symbols represent mean 50\% PWT \pm SEM while bars represent mean percentage maximum anti-allodynia \pm SEM. ${ }^{\# \#} P<0.01,{ }^{\# \#} P<0.001$ compared to vehicle (Veh) treated animals, $* P<0.05, * * P<0.01, * * * P<0.001$ compared to cisplatin treated controls, two-way repeated measures ANOVA followed by post hoc Bonferroni's analysis. $n=6$ rats per group. 
Figure 3: Effect of daily treatment of rats with 6-methoxyflavone (6-MF) at $25 \mathrm{mg} / \mathrm{kg}(6-\mathrm{MF}-25)$, $50 \mathrm{mg} / \mathrm{kg}(6-\mathrm{MF}-50)$, and $75 \mathrm{mg} / \mathrm{kg}$ (6-MF-75) and gabapentin (GBP) at $75 \mathrm{mg} / \mathrm{kg}$ (GBP-75) on the expression of cisplatin-induced thermal hypoalgesia [increased response latency to the thermal stimulus in the hotplate paradigm (paw thermal threshold; PTT in s)] in the hindpaws after weekly i.p. injection of cisplatin at $3.0 \mathrm{mg} / \mathrm{kg}$ (Cis-3) for four consecutive weeks. (A) Temporal development of cisplatin-induced thermal hypoalgesia in the hindpaws. (B) Effect of 6-MF and gabapentin on cisplatin-induced expression of thermal hypoalgesia. (C) The percentage antihypoalgesia of 6-MF and gabapentin. Symbols represent reaction latency as PTT \pm SEM while bars represent mean percentage maximum anti-hypoalgesia \pm SEM. ${ }^{\#} P<0.05,{ }^{\# \#} P<0.01,{ }^{\# \#} P<$ 0.001 compared to vehicle-treated animals, $* P<0.05, * * P<0.01$, $* * * P<0.001$ compared to cisplatin treated controls, two-way repeated measures ANOVA followed by post hoc Bonferroni's analysis. $n=6$ rats per group.

Figure 4: (A) Effect of daily treatment of rats with 6-methoxyflavone (6-MF) at $25 \mathrm{mg} / \mathrm{kg}$ (6-MF25), $50 \mathrm{mg} / \mathrm{kg}$ (6-MF-50), and $75 \mathrm{mg} / \mathrm{kg}$ (6-MF-75) and gabapentin (GBP) at $75 \mathrm{mg} / \mathrm{kg}$ (GBP-75) on the rotarod performance after weekly i.p. injection of cisplatin at $3.0 \mathrm{mg} / \mathrm{kg}$ (Cis-3) for four consecutive weeks. (B) The percentage motor incoordination of 6-MF and gabapentin. Symbols represent mean endurance latency $(s) \pm$ SEM while bars represent mean percentage maximum motor incoordiantion \pm SEM across three test trials. $* P<0.05$, $* * * P<0.001$ compared to vehicletreated (Veh) controls, two-way repeated measures ANOVA followed by post hoc Bonferroni's analysis. $n=6$ rats per group.

Figure 5: Effect of daily treatment of rats with 6-methoxyflavone (6-MF) at $25 \mathrm{mg} / \mathrm{kg}(6-\mathrm{MF}-25)$, $50 \mathrm{mg} / \mathrm{kg}$ (6-MF-50), and $75 \mathrm{mg} / \mathrm{kg}$ (6-MF-75) and gabapentin (GBP) at $75 \mathrm{mg} / \mathrm{kg}$ (GBP-75) on the footprint analysis after weekly i.p. injection of cisplatin at $3.0 \mathrm{mg} / \mathrm{kg}$ (Cis-3) for four consecutive weeks. Data are expressed as mean \pm S.E.M. of overlap between forepaw and hindpaw placement (paw overlap) (A), and the distance of forward movement between each stride (stride length) (B). $* * * P<0.001$ compared to vehicle-treated (Veh) animals, two-way repeated measures ANOVA followed by post hoc Bonferroni's analysis. $n=6$ rats per group. 


\section{FIGURES}

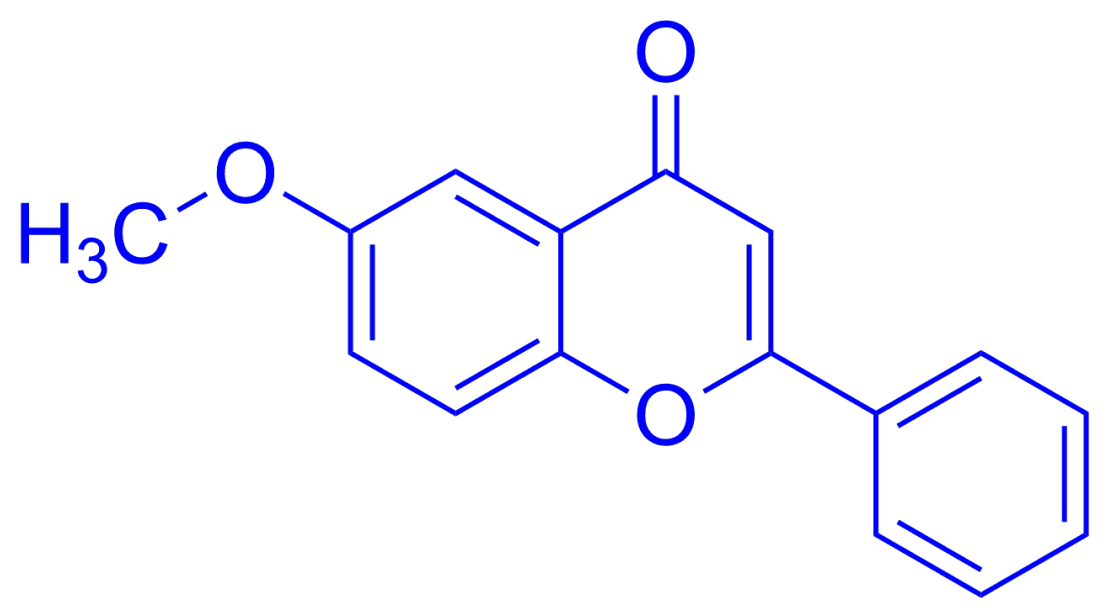

Figure 1 

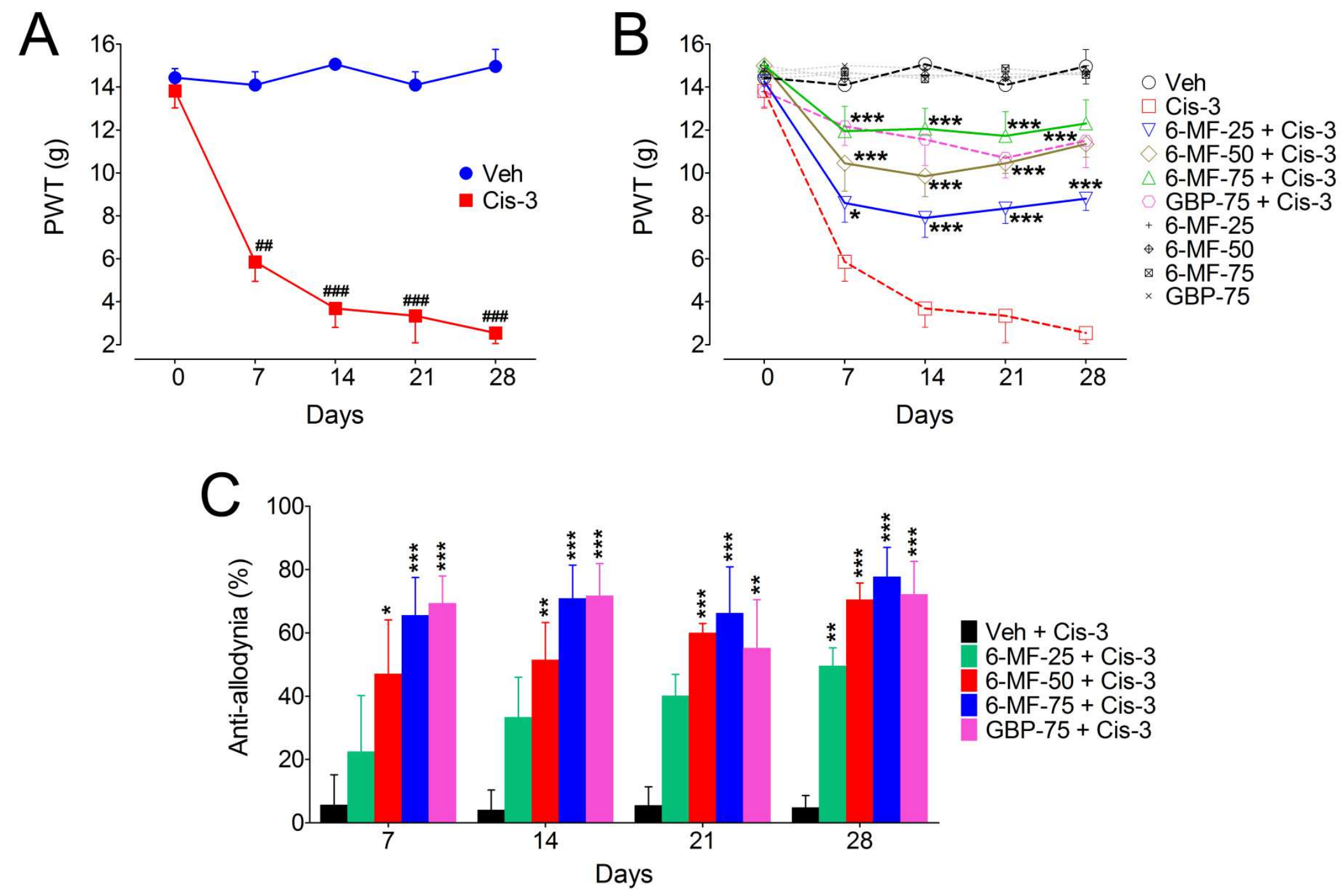

Figure 2 

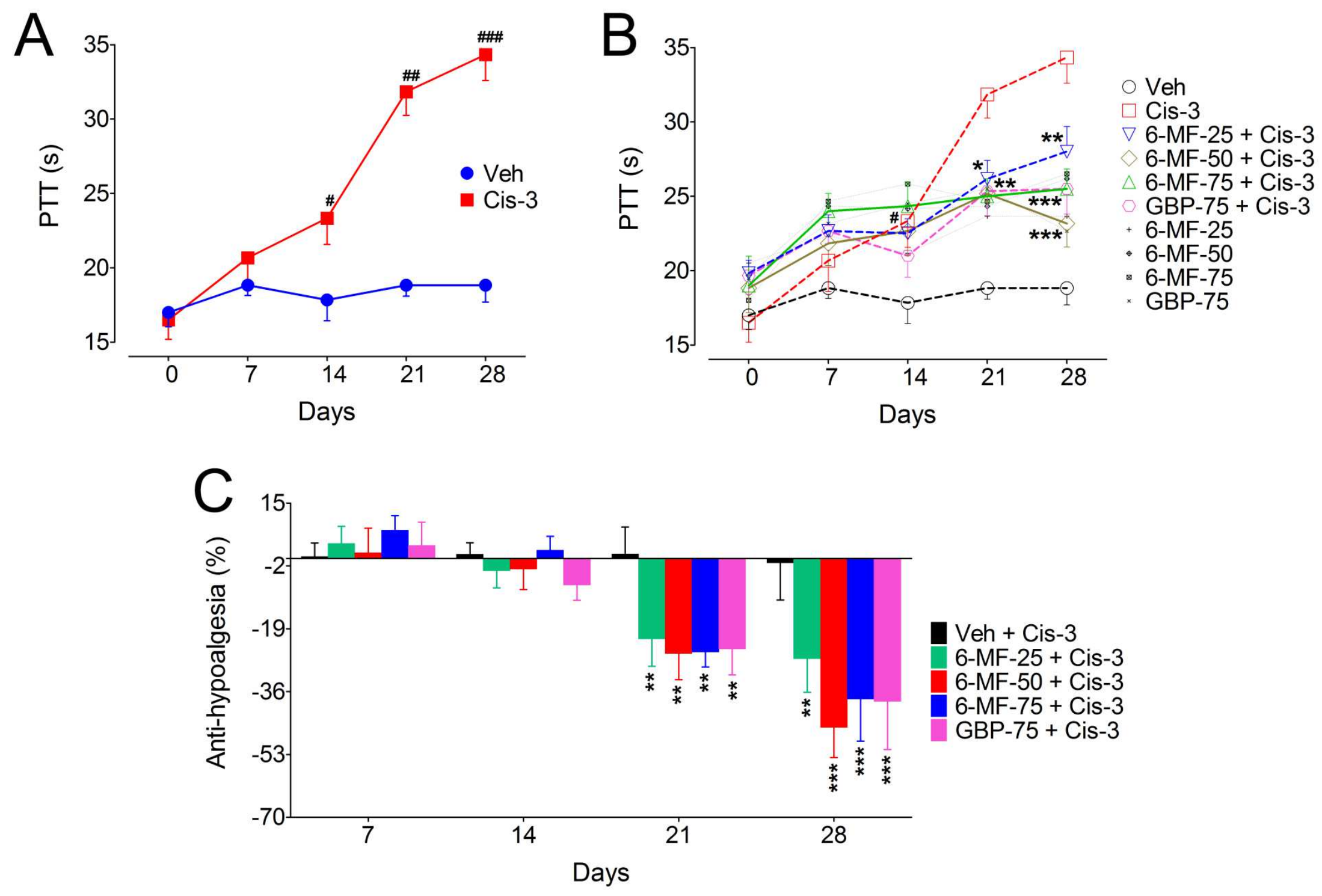

Figure 3 

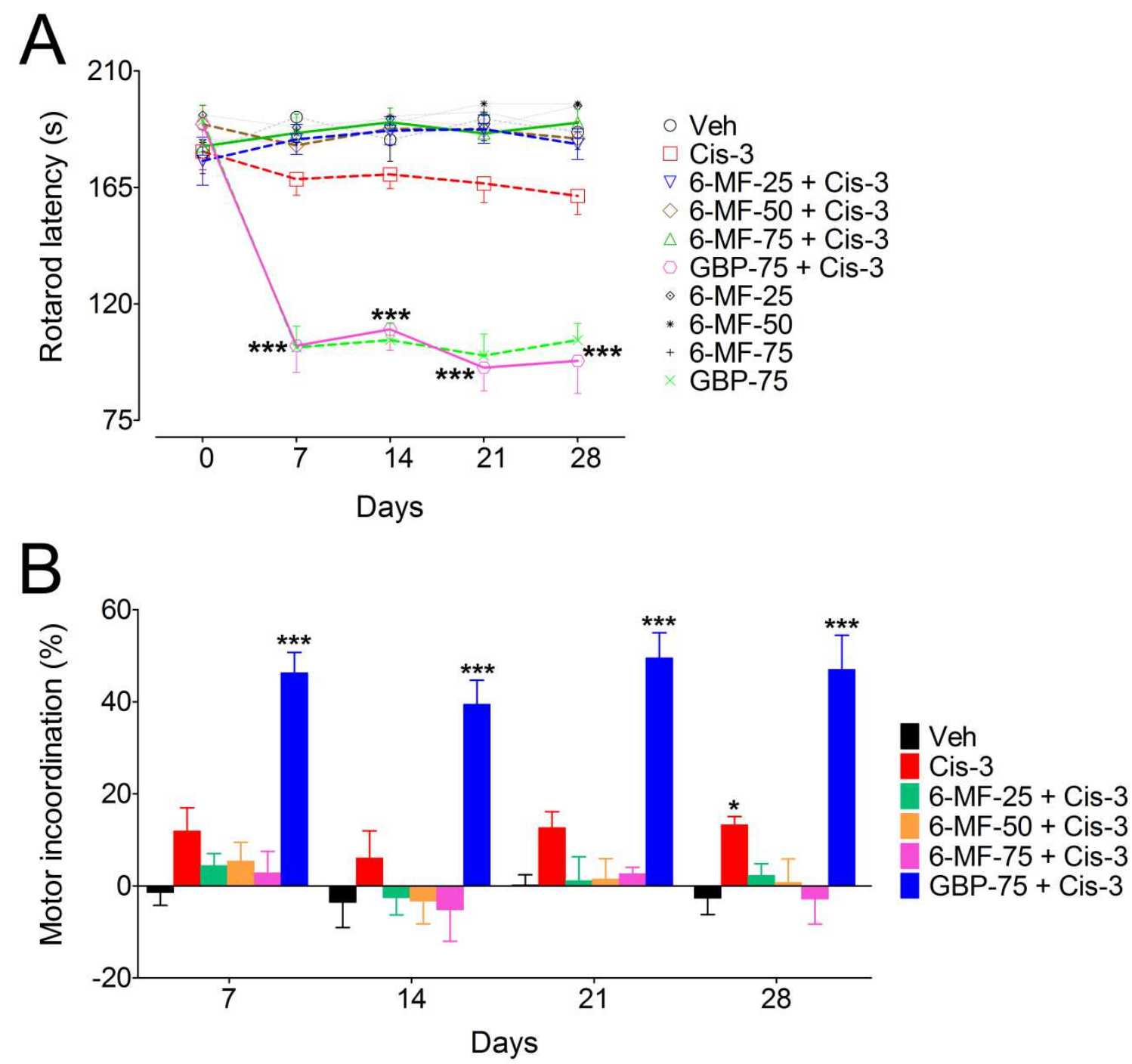

Figure 4 

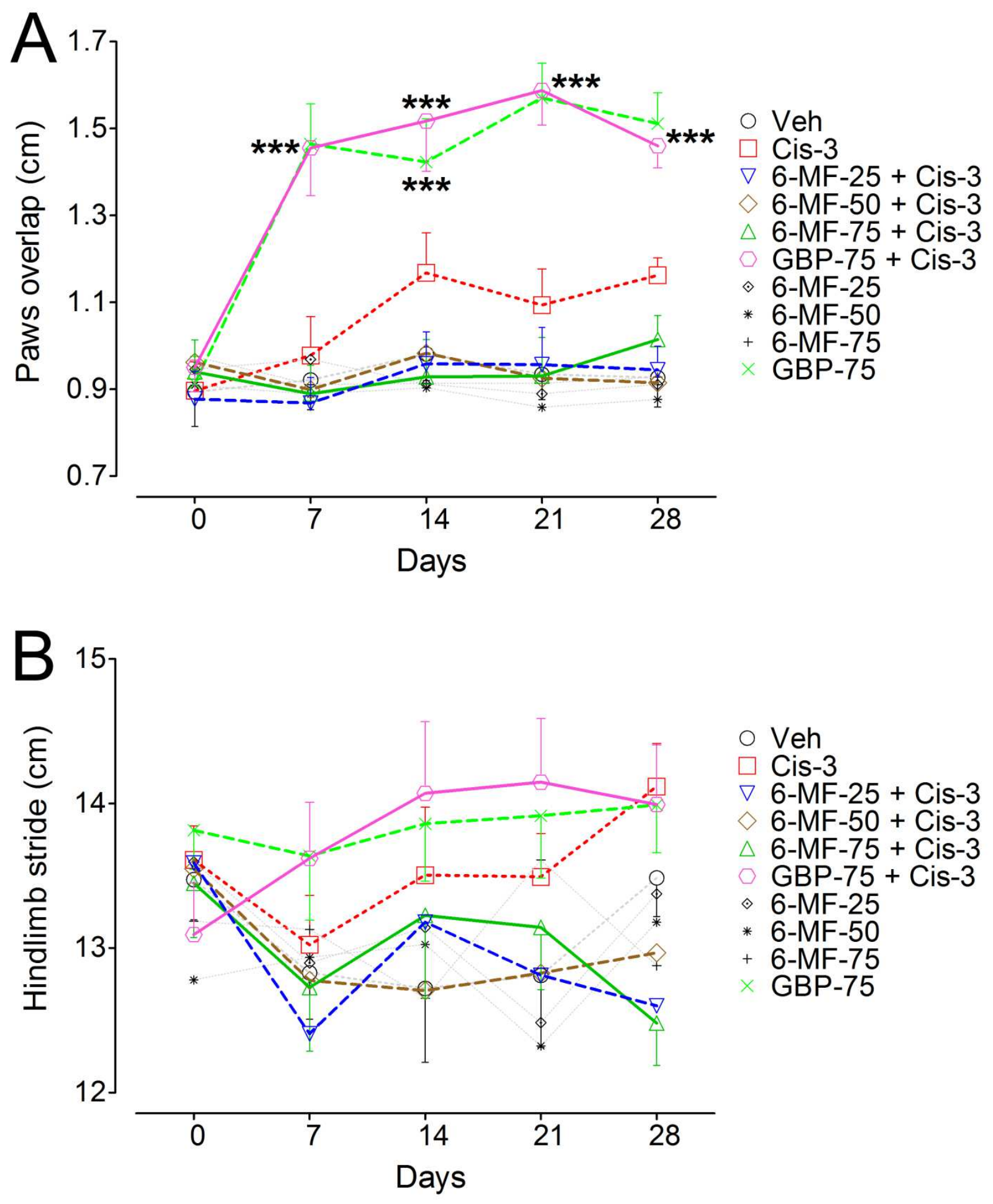

Figure 5 
Table 1: Antinociceptive effect of 6-methoxyflavone (6-MF) in the mouse abdominal constriction test

\begin{tabular}{lll}
\hline Treatment & Dose & Antinociception (\%) \\
\hline Vehicle & $1 \mathrm{~mL} / \mathrm{kg}$ & $5.7 \pm 1.7$ \\
\hline Diclofenac & $50 \mathrm{mg} / \mathrm{kg}$ & $53.8 \pm 6.1^{* * *}$ \\
\hline $6-\mathrm{MF}$ & $10 \mathrm{mg} / \mathrm{kg}$ & $30.6 \pm 3.1^{* * *}$ \\
& $25 \mathrm{mg} / \mathrm{kg}$ & $44.3 \pm 4.2^{* * *}$ \\
& $50 \mathrm{mg} / \mathrm{kg}$ & $52.9 \pm 4.4^{* * *}$ \\
& $75 \mathrm{mg} / \mathrm{kg}$ & $60.9 \pm 3.4^{* * *}$
\end{tabular}

Data expressed as mean percentage antinociception \pm SEM. Oneway ANOVA followed by Dunnett's post hoc test. ${ }^{* * *} P<0.001$, compared to vehicle control. $n=8$ mice per group. 
Table 2: Antinociceptive effect of 6-methoxyflavone (6-MF) in the mouse hotplate and tail immersion paradigms

\begin{tabular}{|c|c|c|c|c|c|}
\hline \multirow{2}{*}{ Paradigm } & \multirow{2}{*}{ Treatment } & \multirow{2}{*}{ Dose } & \multicolumn{3}{|c|}{ Antinociception (\%) } \\
\hline & & & $30 \mathrm{~min}$ & $60 \mathrm{~min}$ & $90 \mathrm{~min}$ \\
\hline \multirow{6}{*}{ 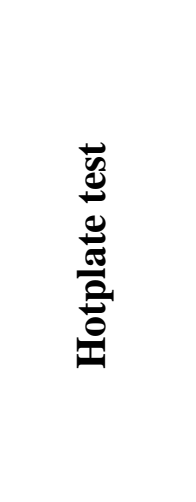 } & Vehicle & $1 \mathrm{~mL} / \mathrm{kg}$ & $5.9 \pm 1.1$ & $5.7 \pm 1.2$ & $5.9 \pm 1.0$ \\
\hline & Morphine & $5 \mathrm{mg} / \mathrm{kg}$ & $50.3 \pm 4.4^{* * *}$ & $27.2 \pm 2.8^{* * *}$ & $15.1 \pm 1.1^{* *}$ \\
\hline & 6-MF & $10 \mathrm{mg} / \mathrm{kg}$ & $19.1 \pm 1.3^{* * *}$ & $14.6 \pm 1.9^{* *}$ & $11.1 \pm 0.8$ \\
\hline & & $25 \mathrm{mg} / \mathrm{kg}$ & $27.4 \pm 2.6^{* * * *}$ & $21.0 \pm 2.5^{* * * *}$ & $16.5 \pm 0.7^{* * *}$ \\
\hline & & $50 \mathrm{mg} / \mathrm{kg}$ & $33.1 \pm 2.3^{* * *}$ & $28.5 \pm 1.4^{* * *}$ & $22.8 \pm 1.7^{* * *}$ \\
\hline & & $75 \mathrm{mg} / \mathrm{kg}$ & $42.9 \pm 2.5^{* * *}$ & $37.3 \pm 1.5^{* * *}$ & $28.3 \pm 2.4^{* * *}$ \\
\hline \multirow{6}{*}{ 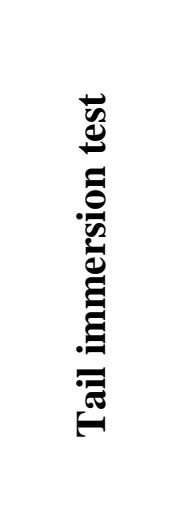 } & Vehicle & $1 \mathrm{~mL} / \mathrm{kg}$ & $3.5 \pm 0.8$ & $4.2 \pm 1.1$ & $3.6 \pm 1.0$ \\
\hline & Morphine & $5 \mathrm{mg} / \mathrm{kg}$ & $57.2 \pm 3.5^{* * *}$ & $44.2 \pm 2.2^{* * *}$ & $34.7 \pm 2.0^{* * *}$ \\
\hline & 6-MF & $10 \mathrm{mg} / \mathrm{kg}$ & $22.3 \pm 3.7^{* * * *}$ & $13.2 \pm 2.0^{*}$ & $10.5 \pm 1.3$ \\
\hline & & $25 \mathrm{mg} / \mathrm{kg}$ & $33.5 \pm 4.5^{* * *}$ & $25.5 \pm 2.3^{* * *}$ & $17.4 \pm 2.9^{* * *}$ \\
\hline & & $50 \mathrm{mg} / \mathrm{kg}$ & $41.4 \pm 3.7^{* * *}$ & $31.0 \pm 2.5^{* * *}$ & $23.0 \pm 2.3^{* * *}$ \\
\hline & & $75 \mathrm{mg} / \mathrm{kg}$ & $54.9 \pm 3.4^{* * *}$ & $43.4 \pm 2.6^{* * *}$ & $32.9 \pm 2.6^{* * *}$ \\
\hline
\end{tabular}

Data expressed as mean percentage antinociception \pm SEM. Two-way repeated measures ANOVA followed by Bonferroni's post hoc test. ${ }^{*} P<0.05,{ }^{* *} P<0.01,{ }^{* * *} P<0.001$, compared to vehicle-treated control. $n=8$ mice per group. 